\section{Annals of Applied Microbiology \& Biotechnology Journal}

\section{Article Information}

Received date: Sep 26, 2017 Accepted date: Oct 06, 2017

Published date: Oct 12, 2017

${ }^{*}$ Corresponding author(s)

Li Yu, Professor, Division of Livestock Infectious Diseases, State Key Laboratory of Veterinary Biotechnology, Harbin Veterinary Research Institute, Chinese Academy of Agricultural Sciences, 427 Maduan Street, Harbin 150001, P.R. China,

Tel: +86-451-51051738;

Fax: +86-451-51997166;

Email: liyu@hvri.ac.cn

Rui Wu, College of Animal Science and Veterinary Medicine, Heilongjiang Bayi Agricultural University, Daqing High-tech Industrial Development Zone, Daqing, 163319, P.R. China,

Tel: + 86-4596819191;

Email: fuhewu@126.com

Distributed under Creative Commons CC-BY 4.0

Keywords M. leachii; Bovine mastitis; Pathogenicity

Article DOI 10.36876/aamb.1003

\title{
Mycoplasma leachii Causes Bovine Mastitis: Evidence from Clinical Symptoms, Histopathology and Immunohistochemistry
}

Jitao Chang ${ }^{1}$, Debin Yu ${ }^{2}$, Jianbin Liang ${ }^{2}$, Jia Chen ${ }^{2}$, Fang Wang ${ }^{1}$, Zhigang Jiang ${ }^{1}$, Xijun $\mathrm{He}^{3}$, Rui $\mathrm{Wu}^{2 \star}$ and $\mathrm{Li} \mathrm{Yu^{1 \star }}$

${ }^{1}$ Division of Livestock Infectious Diseases, State Key Laboratory of Veterinary Biotechnology, Harbin Veterinary Research Institute, Chinese Academy of Agricultural Sciences, P.R. China

${ }^{2}$ College of Animal Science and Veterinary Medicine, Heilongjiang Bayi Agricultural University, P.R. China ${ }^{3}$ Pathology Laboratory, Harbin Veterinary Research Institute, Chinese Academy of Agricultural Sciences, P.R. China

\section{Abstract}

Twelve quarters of six lactating cows were inoculated with Mycoplasma leachii strain GN407 through intramammary ductal infusion, and another twelve quarters were inoculated with Mycoplasma culture medium as controls. One lactating cow was used as negative control, in which two quarters were inoculated with Mycoplasma culture medium, and another two quarters were not inoculated with any medium. Clinical observations, histopathology and Immunohistochemistry (IHC) detection were performed on Post Inoculation Days (PIDs) 3, 6 and 9 to elucidate the pathogenicity of M. leachii in bovine mastitis. From PIDs 3 to 9 , twelve inoculated quarters developed mild to severe clinical mastitis and mammary tissue histopathological changes, including inflammatory cell infiltration and architectural destruction of mammary gland ducts; on PID 9, the control quarters also developed mild mastitis and histopathological changes. Throughout the experimental period, the quarters of the negative control cow were clinically and pathologically normal. The $M$. leachii antigen was detected by IHC in the mammary tissues of the inoculated quarters as a weak signal on PID 6 and as a strong signal on PID 9; on PID 9, the M. leachii IHC signal was also detected in mammary gland epithelial cells of the control quarters of the inoculated cattle. The $M$. leachii antigen was not detected in the mammary tissues from the quarters of the negative control cow on PID 9. In conclusion, direct histological and immunohistochemical evidence confirmed that $M$. leachii causes clinical bovine mastitis through histopathological lesions induced by the invasion of the pathogen into mammary gland cells and inflammatory cell infiltration.

\section{Introduction}

Bovine mastitis is one of the costliest diseases affecting dairy farming, and its losses are calculated based on reduced milk production, discarded milk, increased cull rate, pharmacologic costs and increased labor. Many microbial species, such as Escherichia coli, Klebsiella pneumoniae, Streptococcus agalactiae and Staphylococcus aureus, are common causes of bovine mastitis [1] Mycoplasma spp. are also pathogens associated with bovine mastitis [2,3]. Mycoplasma-induced mastitis was first reported in England by Davidson and Stuart [4] and has since been reported on all continents. Mycoplasma bovis is the most prevalent Mycoplasma species causing bovine mastitis [3,5]. Additionally, Mycoplasma leachii ( $M$. leachii), a new species designation for Mycoplasma sp. bovine group 7 [6], has been isolated from milk samples obtained from cows with mastitis [7-9], and its mild clinical mastitis phenotype was reproduced by infusing $M$. leachii cultures into one quarter of a lactating cow [7], suggesting that M. leachii is a new possible cause of bovine mastitis. However, direct histopathological and immunohistochemical evidence was not presented in the previous pathogenicity study of $M$. leachii [7]; therefore, $M$. leachii has not been proven to be the direct cause of the mild mastitis previously observed in a cow [7]. Since there is insufficient evidence for an association between $M$. leachii infection and bovine mastitis, additional inoculated cows and direct histopathological and immunohistochemical detection should be performed to determine the pathogenicity of $M$. leachii in bovine mastitis.

\section{Materials and Methods}

\section{Ethics statement}

The animal experiments in this study were reviewed and approved by the Animal Care and Use Committee of the Harbin Veterinary Research Institute (HVRI) of the Chinese Academy of Agricultural Sciences (CAAS) on 2 November 2015 (approval number SQ2015112). All animals were housed and cared for in an accredited facility at the HVRI in accordance with local and institutional policies. 


\section{Mycoplasma strain and culture production}

M. leachii strain GN407, which was originally isolated from the joint fluid of arthritic calves in Heilongjiang Province of China in 2010, was passaged 4 times before triple plaque purification. The final titer was $1 \times 10^{8}$ color-changing units per milliliter $(\mathrm{CCU} / \mathrm{ml})$. In $l p p A$ gene sequence analyses, the GN407 strain shared $99.6 \%$, $95.1 \%$, and $69.6 \%$ nt identity to $M$. leachii representative strain PG50, M. mycoides subsp. mycoides small colony type, and M. capricolum subsp. capricolum, respectively $[10,11]$.

\section{Animals and experimental inoculation}

Seven lactating Holstein breed cows without subclinical mastitis in the current lactation and with no antibodies against $M$. leachii were selected for inoculation with M. leachii GN407 [11] cultures to evaluate the pathogenicity of M. leachii in bovine mastitis. The
California Mastitis Test (CMT) was used to detect subclinical mastitis in cows. ELISA and western blot using expressed LPPA protein as an antigen were performed to detect antibodies against $M$. leachii; the LPPA protein was prepared by Wang Guanbo and co-workers in our laboratory (unpublished data). Twelve quarters of six lactating cows (left fore and hind quarters of each cow) were inoculated with $5 \mathrm{ml}$ of fresh culture containing $1 \times 10^{8} \mathrm{CCU} / \mathrm{ml}$ of $M$. leachii strain GN407 through intramammary ductal infusion, and another twelve quarters (right fore and hind quarters of each cow) were inoculated with Mycoplasma culture medium (Becton, Dickinson and Companay Sparks, MD 21152 USA) as a control. As a negative control animal, two quarters of one lactating cow (left fore and hind quarters) were inoculated with $5 \mathrm{ml}$ of Mycoplasma culture medium, and another two quarters (right fore and hind quarters) were not inoculated with any medium (Table 1).

Table 1: Inoculation of lactating cows with passage cultures of $M$. leachii strain GN407 via the intramammary route and detection of pathogens in mammary samples from the inoculated cows.

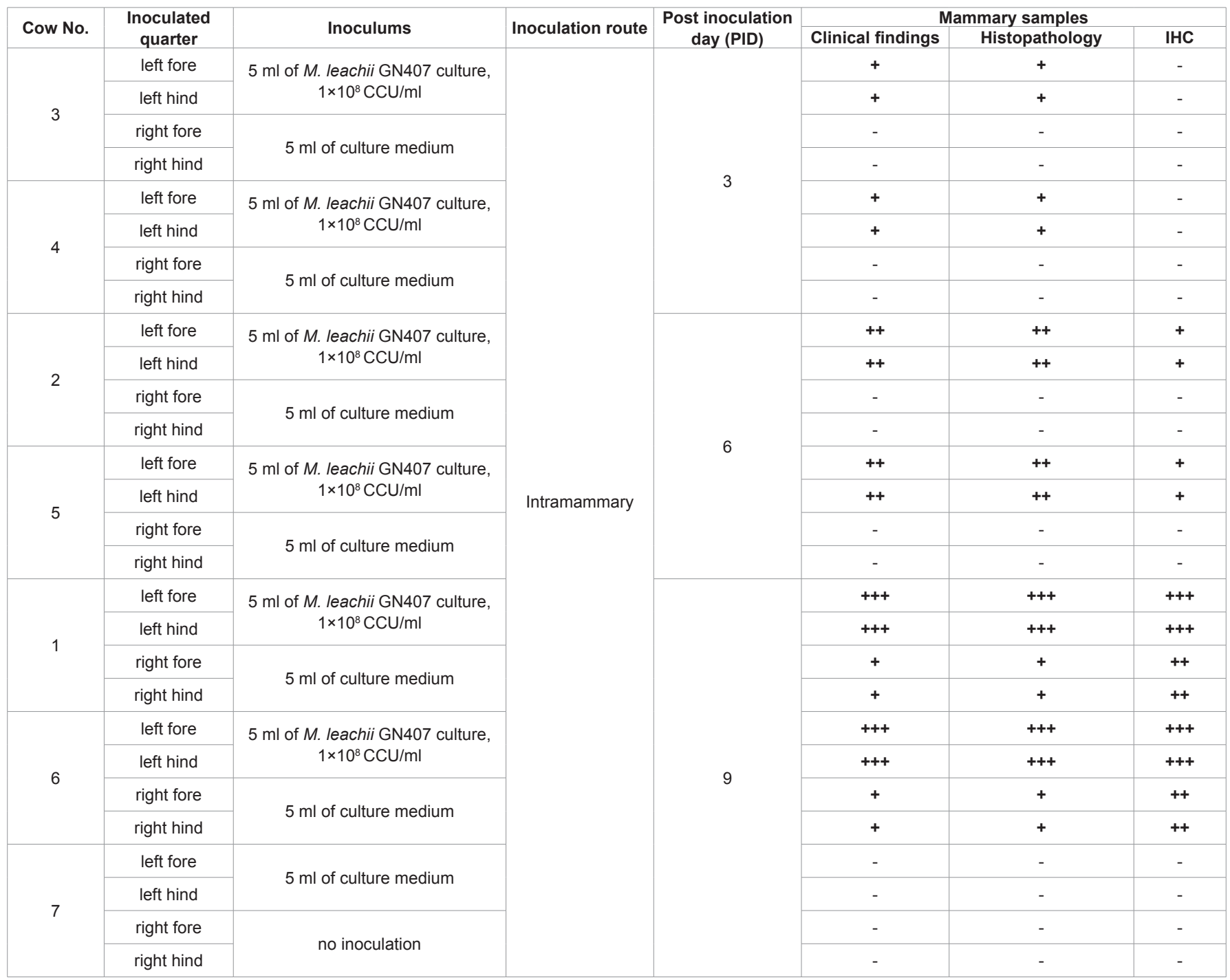

"-" Negative for detection using the corresponding assay.

"+" Positive for detection using the corresponding assay; "+" mildly or weakly positive;

“++" moderately positive; "+++" severely or strongly positive. 


\section{Necropsy and sampling}

On post inoculation days (PIDs) 3, 6 and 9, milk samples were collected from all inoculated cows for PCR detection and cultural isolation of $M$. leachii. The samples were simultaneously plated on Columbia agar (Oxoid, Basingstoke, UK) with 5\% sheep blood and incubated at $37^{\circ} \mathrm{C}$ in $5 \% \mathrm{CO}_{2}$ for isolation of other bacteria. Cows No. 3 and 4, 2 and 5, and 1, 6 and 7 were euthanized on PIDs 3, 6 and 9 , respectively, and subjected to necropsy. Mammary gland tissue samples were collected and fixed in $4 \%$ neutral-buffered formalin for histopathology and Immunohistochemistry (IHC) assays.

\section{Histopathology}

The formalin-fixed tissues were embedded in paraffin wax, sliced to a thickness of $4 \mu \mathrm{m}$ and stained with Hematoxylin and Eosin (H\&E) for histological examination. Analyses were subsequently performed by the Pathology Laboratory of Animal Infectious Disease Diagnostic Centre, Harbin Veterinary Research Institute, Chinese Academy of Agricultural Sciences.

\section{PCR}

According to a previously described method [12], the specific primer pair P67BG7-L: GGTAATTCGAATAATGATCCT/ P67BG7-R: TAAGTTTATTGAAT -TAAAGCG was used for PCR amplification of the $l_{p p A}$ gene with an annealing temperature of $55^{\circ} \mathrm{C}$ to detect $M$. leachii in samples.

\section{Immunohistochemistry (IHC)}

Monoclonal antibody (mAb) 1F2, which was prepared by Wang Guanbo and co-workers in our laboratory (unpublished data), was used for IHC detection. The isotype of $1 \mathrm{~F} 2$ is of the $\operatorname{IgG} 1 / \kappa$-type subclass. Western blot showed that mAb 1F2 specifically bound to M. leachii GN407 but not to other Mycoplasma species (such as Mycoplasma bovis, Mycoplasma mycoides subsp. capricolum, Mycoplasma ovipneumoniae, Mycoplasma. mycoides subsp. Mycoides small colony type, or Mycoplasma capricolum subsp. capripneumoniae), and the titer of this antibody was $1: 10^{5}$ based on ELISA detection. For all immunohistochemical reactions, the Avidin: Biotinylated enzyme Complex (ABC) method was applied. We used formalin-fixed samples, mAb $1 F 2$ and normal mouse $(B A L B / c)$ serum as a negative control. Subsequent work was performed by the Pathology Laboratory of Animal Infectious Disease Diagnostic Centre of Harbin Veterinary Research Institute, Chinese Academy of Agricultural Sciences.

\section{Results}

Clinical manifestations of the quarters of all M. leachiiinoculated cows were observed throughout the experimental period. Histopathology and IHC detection of the mammary tissues were performed on PIDs 3, 6 and 9. The clinical signs and histopathology of the M. leachii-inoculated quarters exhibited a gradual progression to severe mastitis over the 9-day experimental period (Table 1, Figure 1), and the M. leachii antigen was detected in mammary tissue from the inoculated quarters of the affected cows on PIDs 6 and 9 by IHC (Table 1, Figure 2). For the control quarters

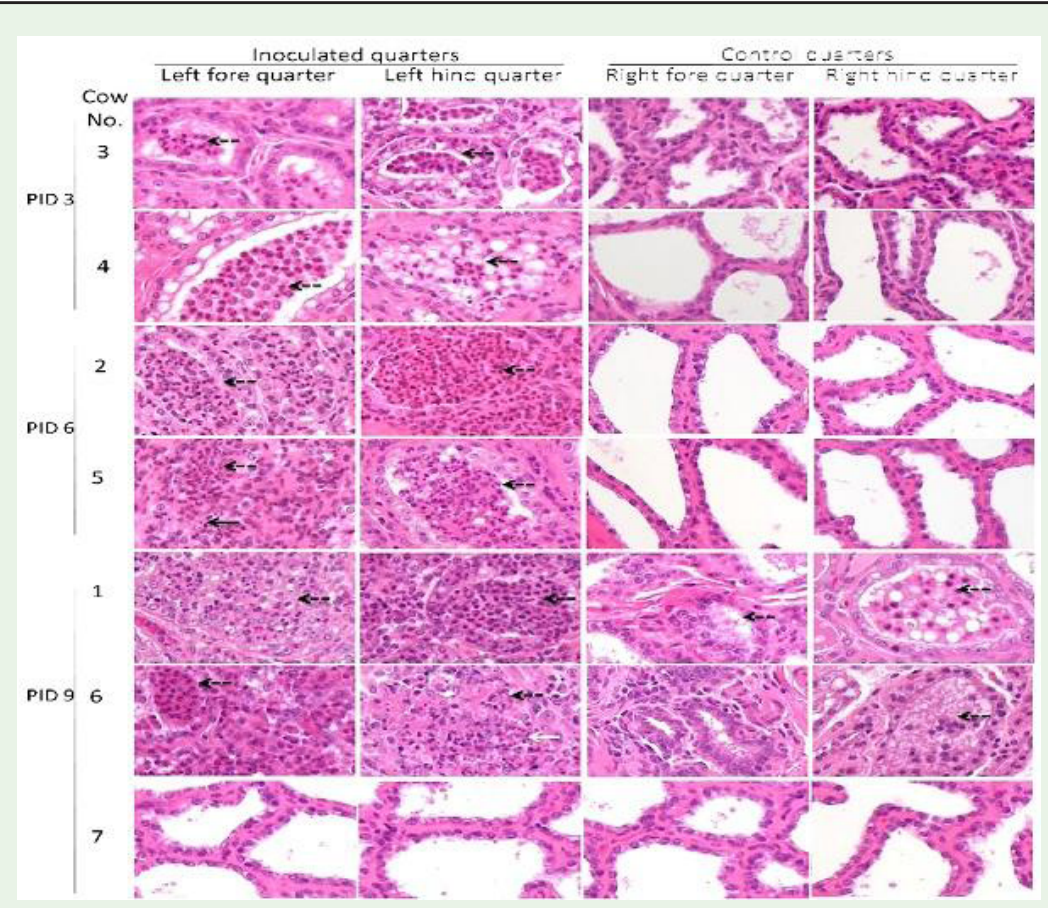

Figure 1: Histopathology of mammary tissue samples from $M$. leachii-inoculated cows.

The left fore and hind quarters of each cow were inoculated with $5 \mathrm{ml}$ of a liquid culture of $M$. leachii GN407 via intramammary infusion, and the right fore and hind quarters of each cow were inoculated with $5 \mathrm{ml}$ of culture medium via the same route to serve as a negative control. Neutrophilic granulocyte infiltration was present in all inoculated quarters on PIDs 3,6 and 9 and in the control quarters on PID 9 (black dotted arrow). The structures of some mammary gland ducts were destroyed (black solid arrow). Necrosis was observed in the mammary gland tissue from the left hind quarter of cow No. 6 (white solid arrow). The control quarters of the experimental cows on PIDs 3 and 6 and the quarters of negative control cow No. 7 on PID 9 were histopathologically normal (200x). 


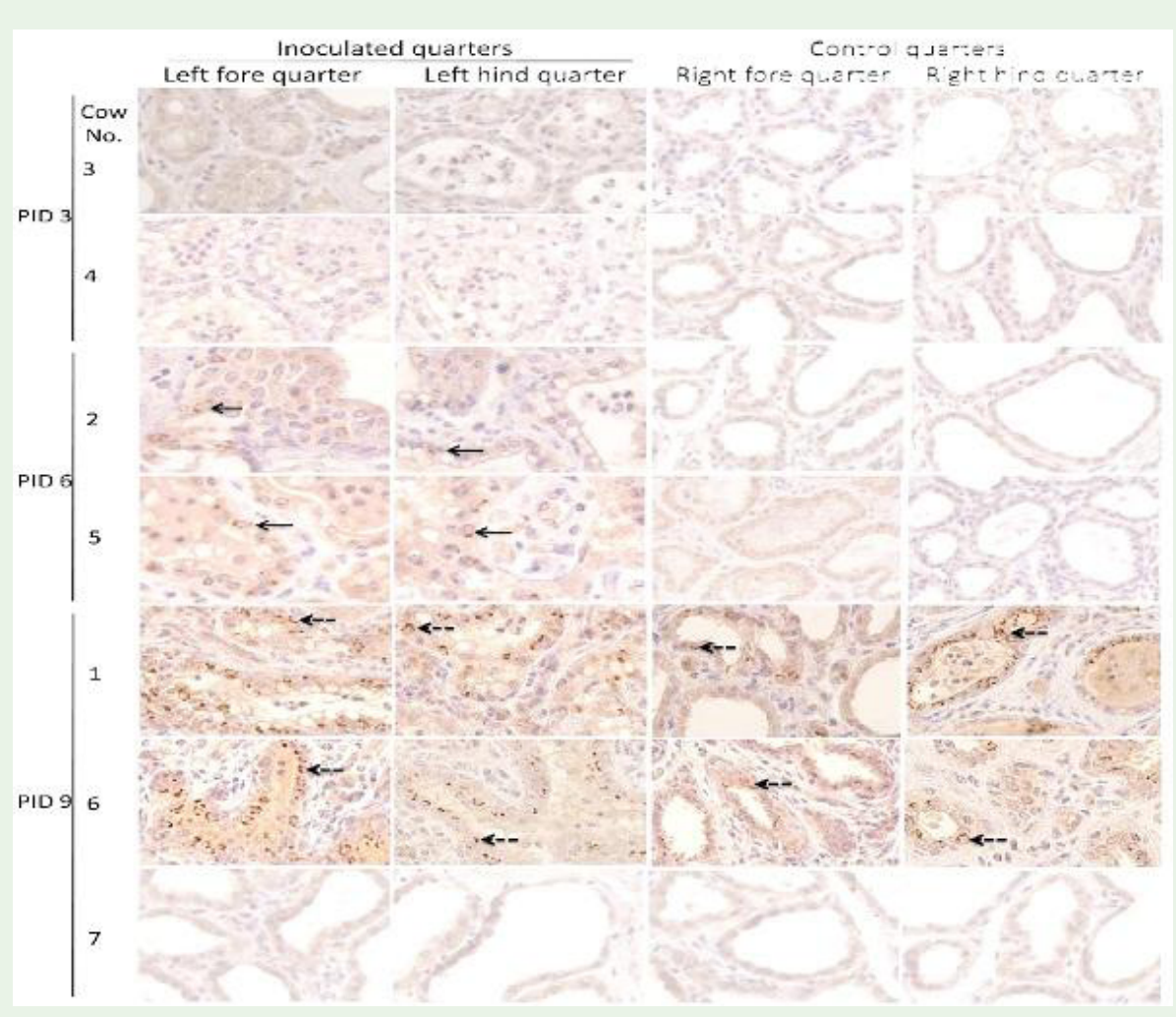

Figure 2: IHC assay for the M. leachii antigen in mammary tissue samples from $M$. leachii-inoculated cows.

The M. leachii antigen was not detected in any of the inoculated or control quarters from cows 3 and 4 on PID 3. Weak positive labeling with an M. leachii-specific monoclonal antibody (mAb) was observed in the inoculated quarters from cows 2 and 5 (solid arrow) on PID 6, but the M. leachii antigen was not detected in any of the control quarters from cows 2 and 5. On PID 9, strongly positive labeling with the M. leachii-specific mAb was observed in all inoculated and control quarters from cows 1 and 6 . Extensive staining for the $M$. leachii antigen was observed on the surface or in the cytoplasm of mammary epithelial cells (dotted arrow). The $M$. leachii antigen was not detected in the mammary tissues from the quarters of negative control cow No. 7 on PID 9 (200x).

of the M. leachii-inoculated cows, they were histopathologically and immunohistochemically negative on PIDs 3 and 6 but they developed mild mastitis and histopathological changes on PID 9, and the M. leachii IHC signal was also detected in mammary gland epithelial cells of these control quarters (Table 1, Figures 1 and 2). Throughout the experimental period, however, the quarters of the negative control cow were clinically and histopathologically normal, and the M. leachii antigen was not detected in the mammary tissues of the control cow on PID 9 (Table 1, Figures 1 and 2). The clinical signs of the affected mammary glands were swelling and firmness, the produced milk was yellow and contained large ropy clots, and the milk yield of the inoculated quarters was markedly decreased. These results, particularly the detection of the M. leachii antigen in the mammary gland epithelial cells of the inoculated cows, indicated that the mammary gland lesions were directly caused by M. leachii.

On PID 3, all twelve M. leachii-inoculated quarters of the six experimental cows (Nos. 1-6) developed mild clinical mastitis, whereas the twelve control quarters of the six inoculated cows were normal. Cows 3 and 4 were euthanized on PID 3 and subjected to necropsy. Histopathological changes, primarily Neutrophilic granulocyte infiltration, were observed in the mammary tissues from all four inoculated quarters (Table 1, Figure 1), but the M. leachii antigen was not detected (Table 1, Figure 2). Histopathological changes and the $M$. leachii antigen were not detected in the mammary epithelial cells and mammary ducts of the control quarters of cows 3 and 4 (Table 1, Figures 1 and 2), indicating that M. leachii did not invade mammary cells during the early stage of mastitis.

On PID 6, the eight inoculated quarters of the remaining four experimental cows (Nos. 1, 2, 5 and 6) exhibited moderate clinical mastitis, and all eight control quarters remained normal. Cows 2 and 5 were necropsied on PID 6, and the histopathological examination of the four inoculated quarters showed moderate and diffuse neutrophilic granulocyte infiltration (Table 1, Figure 1) and mild destruction of some mammary gland duct structures in the left fore quarter of cow No. 5 (Figure 1). At this time, the M. leachii antigen was detected as a weak signal in the mammary epithelial cells of the four inoculated quarters from cows 2 and 5 (Table 1, Figure 2), but histopathological changes and the $M$. leachii antigen were still not detected in any of the four control quarters of cows 2 and 5 (Table 1 , Figures 1 and 2). Thus, $M$. leachii invaded the mammary epithelial cells in the inoculated quarters by PID 6, but it did not spread to the opposite control quarters in the inoculated bodies at that time.

On PID 9, severe clinical mastitis was observed in the four inoculated quarters of the remaining two experimental cows (Nos. 1 and 6). Importantly, all four control quarters of cows 1 and 6 had also developed mild mastitis (Table 1 ) at that time. Cows 1 and 6 were necropsied for a histopathological examination, and more extensive 
and severe Neutrophilic infiltration and destruction of the mammary gland ducts were observed in all four inoculated quarters (Table 1, Figure 1). Additionally, necrosis of mammary epithelial cells was observed in the mammary gland tissue from the left hind quarter of cow No. 6 (Figure 1). The M. leachii antigen was detected as a strong signal in mammary epithelial cells of the four inoculated quarters of cows 1 and 6 (Table 1, Figure 2). In addition, mild histopathological changes were observed (Table 1, Figure 1) and the M. leachii antigen was detected (Table 1, Figure 2) in all four control quarters of cows 1 and 6 on PID 9. Thus, M. leachii propagated abundantly in the mammary epithelial cells of the inoculated quarters on PID 9. Importantly, the pathogen had invaded the adjacent quarter on the opposite side at that time.
On PIDs 3, 6 and 9, the $M$. leachii signal detected via PCR in the milk samples from the infected quarters ranged from weak to strong, and the M. leachii titer also gradually increased (Table 2). The PCR detection and isolation of $M$. leachii from the milk samples of the control quarters was negative on PIDs 3 and 6; however on PID 9, a moderately positive PCR signal was detected in the milk samples of the control quarters of the experimental cows, and $M$. leachii was also isolated (Table 2). These $M$. leachii PCR detection and isolation results were consistent with the clinical, histopathological and immunohistochemical results. Additionally, no pathogenic bacteria were isolated and identified from the milk samples of the infected cows, indicating the absence of bacterial coinfection in the mammary gland tissue.

Table 2: PCR detection and isolation of $M$. leachii from milk samples of the inoculated cows.

\begin{tabular}{|c|c|c|c|c|c|c|c|}
\hline \multirow{3}{*}{ Cow No. } & \multirow{3}{*}{ Inoculated quarter } & \multicolumn{6}{|c|}{ Post Inoculation day (PID) } \\
\hline & & \multicolumn{2}{|r|}{3} & \multicolumn{2}{|r|}{6} & \multicolumn{2}{|c|}{9} \\
\hline & & M. leachii PCR & M. leachii isolation & M. leachii PCR & M. leachii isolation & M. leachii PCR & $\begin{array}{l}\text { M. leachii } \\
\text { isolation }\end{array}$ \\
\hline \multirow{3}{*}{3} & left fore & + & $\begin{array}{c}1 \times 10^{4} \\
\mathrm{CCU} / \mathrm{ml}\end{array}$ & NP & NP & NP & NP \\
\hline & left hind & + & $1 \times 10^{4} \mathrm{CCU} / \mathrm{ml}$ & NP & NP & NP & NP \\
\hline & right hind & - & - & NP & NP & NP & NP \\
\hline \multirow{4}{*}{4} & left fore & + & $1 \times 10^{4} \mathrm{CCU} / \mathrm{ml}$ & NP & NP & NP & NP \\
\hline & left hind & + & $1 \times 10^{4} \mathrm{CCU} / \mathrm{ml}$ & NP & NP & NP & NP \\
\hline & right fore & - & - & NP & NP & NP & NP \\
\hline & right hind & - & - & NP & NP & NP & NP \\
\hline \multirow{3}{*}{2} & left hind & + & $1 \times 10^{4} \mathrm{CCU} / \mathrm{ml}$ & ++ & $1 \times 10^{6} \mathrm{CCU} / \mathrm{ml}$ & NP & NP \\
\hline & right fore & - & - & - & - & NP & NP \\
\hline & right hind & - & - & - & - & NP & NP \\
\hline \multirow{4}{*}{5} & left fore & + & $1 \times 10^{4} \mathrm{CCU} / \mathrm{ml}$ & ++ & $1 \times 106 \mathrm{CCU} / \mathrm{ml}$ & NP & NP \\
\hline & left hind & + & $1 \times 10^{4} \mathrm{CCU} / \mathrm{ml}$ & ++ & $1 \times 106 \mathrm{CCU} / \mathrm{ml}$ & NP & NP \\
\hline & right fore & - & - & - & - & NP & NP \\
\hline & right hind & - & - & - & - & NP & NP \\
\hline \multirow{4}{*}{1} & left fore & + & $\begin{array}{c}1 \times 10^{4} \\
\mathrm{CCU} / \mathrm{ml}\end{array}$ & ++ & $1 \times 10^{6} \mathrm{CCU} / \mathrm{ml}$ & ++++ & $1 \times 10^{8} \mathrm{CCU} / \mathrm{ml}$ \\
\hline & left hind & + & $1 \times 10^{4} \mathrm{CCU} / \mathrm{ml}$ & ++ & $1 \times 10^{6} \mathrm{CCU} / \mathrm{ml}$ & ++++ & $1 \times 10^{8} \mathrm{CCU} / \mathrm{ml}$ \\
\hline & right fore & - & - & - & - & ++ & $1 \times 10^{6} \mathrm{CCU} / \mathrm{ml}$ \\
\hline & right hind & - & - & - & - & ++ & $1 \times 10^{6} \mathrm{CCU} / \mathrm{ml}$ \\
\hline \multirow{3}{*}{6} & left hind & + & $1 \times 10^{4} \mathrm{CCU} / \mathrm{ml}$ & ++ & $1 \times 10^{6} \mathrm{CCU} / \mathrm{ml}$ & ++++ & $1 \times 10^{8} \mathrm{CCU} / \mathrm{ml}$ \\
\hline & right fore & - & - & - & - & ++ & $1 \times 10^{6} \mathrm{CCU} / \mathrm{ml}$ \\
\hline & right hind & - & - & - & - & ++ & $1 \times 10^{6} \mathrm{CCU} / \mathrm{ml}$ \\
\hline \multirow{4}{*}{7} & left fore & - & - & - & - & - & - \\
\hline & left hind & - & - & - & - & - & - \\
\hline & right fore & - & - & - & - & - & - \\
\hline & right hind & - & - & - & - & - & - \\
\hline
\end{tabular}

"++++": Strongly positive in PCR detection; "++": moderately positive in PCR detection; "+": weakly positive in PCR detection

"-": negative in PCR detection and M. leachii isolation; "NP": these cows were slaughtered, and the corresponding detection was not performed.

Citation: Chang J, Yu D, Liang J, Chen J, Wang F, Jiang Z, et al. Mycoplasma leachii Causes Bovine Mastitis: Evidence from Clinical Symptoms, Histopathology and Immunohistochemistry. Ann Appl Microbiol Biotechnol J. 2017; 1(1): 1003

https://dx.doi.org/10.36876/aamb.1003 


\section{Discussion}

Bovine mastitis, causing the decrease in milk production, increased health care costs and increased culling and death rates [13], is responsible for major economic losses on dairy farms worldwide. Moreover, mastitis poses a threat to human health since it may be responsible for zoonoses and food toxin infections [14,15]. Mastitis caused by mycoplasmas is less common than mastitis caused by other bacteria, but it results in severe udder disease [16] and can usually be differentiated from mastitis caused by other bacteria because it exhibits the following features: (1) it is highly contagious; (2) it affects more than one quarter; (3) it causes a significant loss in milk production; (4) it is often refractory to antibiotic treatment; (5) it may result in increased purulence; and (6) affected cows can remain externally normal, with few overt clinical signs, even in severe cases. For these reasons, mycoplasma mastitis is considered untreatable; consequently, culling remains the most common recommendation for its control [3]. Of the approximately 25 mycoplasmas that have been detected in cattle, only a few have been linked to bovine mastitis. Mycoplasma bovis is most prevalent and was first isolated from mastitic cows in 1961 [3]. Other species that have been reported as causes of mycoplasma mastitis include Mycoplasma arginini and $M$. leachii $[3,17]$.

M. leachii was initially isolated from the joint fluid of arthritic calves in southern Queensland, Australia in 1963 [18]. Subsequently, M. leachii was also isolated from calves with polyarthritis and pneumonia, cows with signs of mastitis, aborted fetuses and small ruminant hosts [7-9,19-21]. In China, polyarthritis in calves caused by $M$. leachii was an emerging disease in 2009, and M. leachii strain GN407 was first isolated from the joint fluid of arthritic calves in China by our laboratory $[10,11]$. M. leachii was isolated from milk samples obtained from cows with mastitis [7-9], and its mild clinical mastitis phenotype was reproduced by infusing $M$. leachii cultures into one quarter of a lactating cow [7]. However, the histopathological and immunohistochemical evidence was insufficient to support the pathogen-disease relationship. In this study, we demonstrated that $M$. leachii directly causes clinical bovine mastitis using histopathological and immunohistochemical methods, and we further confirmed that $M$. leachii is one of the causes of bovine mastitis. Because numerous pathogens are responsible for bovine mastitis, with the majority of infections caused by staphylococci, streptococci and enterobacteria, milk samples collected both pre- and post inoculation were plated on Columbia agar for the isolation and identification of other main pathogenic bacteria. No pathogenic bacteria were isolated and identified from the milk samples of the infected cows, indicating the absence of bacterial coinfection in the mammary gland tissue of the experimental cows. Although no other pathogens, including bacteria and viruses, were detected, the histopathological and immunohistochemical evidence from this study is sufficient to support the conclusion that $M$. leachii can directly cause bovine mastitis.

As mentioned above, bovine mastitis caused by mycoplasmas has unique characteristics, including that it often affects more than one quarter. In this study, M. leachii also invaded the adjacent quarter on the opposite side of the inoculated quarters at a later stage of mastitis, indicating that $M$. leachii can spread from the inoculated quarter to the opposite adjacent quarter in the same cow's body. This result is consistent with the characteristic of Mycoplasma mastitis affecting more than one quarter. However, the route of transmission of $M$. leachii in the body is currently unclear. It has been reported that Mycoplasma spp. can spread from one bovine body site to another, presumably via the lymph or peripheral blood system [22-24].

During the 9-day experimental period, the histopathology of all inoculated quarters showed a gradual progression to severe mastitis (Table 1, Figure 1). On PID 3, histopathological changes were observed in the mammary tissues from all four inoculated quarters, but the M. leachii antigen signal was not detected (Table 1, Figure 1). The mechanism underlying this inconsistency is unclear and may be related to mammary immunobiology. The mammary gland immune system consists of a diverse array of physical, cellular, and molecular factors that function in the innate or acquired immune responses. Components of the innate defense system include nonspecific physical barriers of the teat end, pattern recognition receptors, phagocytes (i.e., neutrophils and macrophages), and various soluble factors (i.e., cytokines, complement, and lactoferrin) [25]. In this study, the histological changes observed in the inoculated quarters on PID 3 consisted of neutrophilic granulocyte infiltration, but the M. leachii antigen was not detected. Therefore, the inflammation observed on PID 3 is suggested to be caused by the extracellular propagation of $M$. leachii in mammary ducts. Some $M$. leachii may be phagocytosed and eliminated by inflammatory cells, whereas a small amount of residual $M$. leachii that had colonized the lumen of the mammary ducts had not yet invaded the mammary epithelial cells in the early stage of mastitis. Thus, although histological changes (Neutrophilic granulocyte infiltration) were observed in the inoculated quarters on PID 3, the M. leachii antigen was not detected in the mammary epithelial cells or mammary ducts.

In summary, the pathogenicity of M. leachii in bovine mastitis was investigated using an artificial infection experiment. Direct histological and immunohistochemical evidence confirmed that M. leachii causes clinical mastitis in cows, which results from histopathological lesions induced by the invasion of the pathogen into mammary gland cells and inflammatory cell infiltration. Moreover, M. leachii can spread from the inoculated quarter to the opposite adjacent quarter in the body.

\section{Acknowledgements}

This study was supported by the Natural Science Fund Project of Heilongiiang Province of China (C201348), the Key Technologies R \& D Program of Heilongjiang Province of China (GA12B301), and the National Science and Technology Program Topics of China (2012BAD12B03-3).

\section{References}

1. Zadoks RN, Middleton JR, McDougall S, Katholm J, Schukken YH. Molecular epidemiology of mastitis pathogens of dairy cattle and comparative relevance to humans. J Mammary Gland Biol Neoplasia. 2011; 16: 357-372.

2. Maunsell FP, Woolums AR, Francoz D, Rosenbusch RF, Step DL, Wilson DJ. Mycoplasma bovis infections in cattle. J Vet Intern Med. 2011; 25: 772-783.

3. Nicholas RA, Fox LK, Lysnyansky I. Mycoplasma mastitis in cattle: To cull or not to cull. Vet J. 2016; 216: 142-147.

4. Davidson I, Stuart P. Isolation of a mycoplasma-like organism from an outbreak of bovine mastitis. Vet Rec. 1960; 72: 766

5. Nicholas RA, Ayling RD. Mycoplasma bovis: disease, diagnosis, and control. Res Vet Sci. 2003; 74: 105-112. 
6. Manso-Silván L, Vilei EM, Sachse K, Djordjevic SP, Thiaucourt F, Frey J Mycoplasma leachii sp. nov. as a new species designation for Mycoplasma sp. bovine group 7 of Leach, and reclassification of Mycoplasma mycoides subsp. mycoides LC as a serovar of Mycoplasma mycoides subsp. capri. Int J Syst Evol Microbiol. 2009; 59: 1353-1358.

7. Connole MD, Laws L, Hart RK. Mastitis in cattle caused by a Mycoplasma sp. Aust Vet J. 1967; 43: 157-162.

8. Alexander PG, Slee KJ, McOrist S, Ireland L, Coloe PJ. Mastitis in cows and polyarthritis and pneumonia in calves caused by Mycoplasma species bovine group 7. Aust Vet J. 1985; 62: 135-136.

9. Hum S, Kessell A, Djordjevic S, Rheinberger R, Hornitzky M, Forbes W, et al. Mastitis, polyarthritis and abortion caused by Mycoplasma species bovine group 7 in dairy cattle. Aust Vet J. 2000; 78: 744-750.

10. Liu H, Chang J, Yu L. Polyarthritis in calves caused by Mycoplasma leachi sp. nov in China. Chinese Journal of Preventive Veterinary Medicine. 2010 32: $415-418$

11. Chang JT, Liu HJ, Yu L. Mycoplasma leachii sp. nov. in calves, China. Emerg Infect Dis. 2011; 17: 1772-1773.

12. Frey J, Cheng X, Monnerat MP, Abdo EM, Krawinkler M, Bölske G, et al. Genetic and serological analysis of the immunogenic $67-\mathrm{kDa}$ lipoprotein of Mycoplasma sp. bovine group 7. Res Microbiol. 1998; 149: 55-64.

13. Gomes F, Saavedra MJ, Henriques M. Bovine mastitis disease/pathogenicity: evidence of the potential role of microbial biofilms. Pathog Dis. 2016; 74

14. Blum S, Heller ED, Krifucks O, Sela S, Hammer-Muntz O, Leitner G Identification of a bovine mastitis Escherichia coli subset. Vet Microbiol. 2008; 132: $135-148$.

15. Fernandes JB, Zanardo LG, Galvão NN, Carvalho IA, Nero LA, Moreira MA Escherichia coli from clinical mastitis: serotypes and virulence factors. J Vet Diagn Invest. 2011; 23: 1146-1152.
16. Fox LK, Muller FJ, Wedam ML, Schneider CS, Biddle MK. Clinical Mycoplasma bovis mastitis in prepubertal heifers on 2 dairy herds. Can Vet J. 2008; 49: 1110-1112.

17. González RN, Wilson DJ. Mycoplasmal mastitis in dairy herds. Vet Clin North Am Food Anim Pract. 2003; 19: 199-221.

18. Simmons GC, Johnston LA. Arthritis in calves caused by Mycoplasma sp Australian Veterinary Journal. 1963; 39: 11-14.

19. Hughes KL, Edwards MJ, Hartley WJ, Murphy S. Polyarthritis in calves caused by Mycoplasma sp. Veterinary record. 1966; 78: 276-281.

20. Cottew GS. Mycoplasmas isolated from cattle in Australia. Aust Vet J. 1970; 46: 378-381.

21. Shiel MJ, Coloe PJ, Worotniuk B, Burgess GW. Polyarthritis in a calf associated with a group 7 Mycoplasma infection. Aust Vet J. 1982; 59: 192 193.

22. Jain NC, Jasper DE, Dellinger JD. Cultural characters and serologica relationships of some mycoplasmas isolated from bovine sources. J Gen Microbiol. 1967; 49: 401-410.

23. Biddle MK, Fox LK, Evans MA, Gay CC. Pulsed-field gel electrophoresis patterns of Mycoplasma isolates from various body sites in dairy cattle with Mycoplasma mastitis. J Am Vet Med Assoc. 2005; 227: 455-459.

24. Fox LK, Hancock DD, Mickelson A, Britten A. Bulk tank milk analysis: factors associated with appearance of Mycoplasma sp. in milk. J Vet Med B Infect Dis Vet Public Health. 2003; 50: 235-240.

25. Aitken SL, Corl CM, Sordillo LM. Immunopathology of mastitis: insights into disease recognition and resolution. J Mammary Gland Biol Neoplasia. 2011 16: 291-304. 